\title{
KOMBINASI POSISI KEPALA 30 DAN PASIVE RANGE OF MOTION TERHADAP SKOR NIHSS PADA PASIEN STROKE
}

\author{
${ }^{1}$ Arif Hendra Kusuma, ${ }^{2}$ Atika Dhiah Anggraeni \\ ${ }^{1}$ STIKes Serulingmas Cilacap, ${ }^{2}$ Univesitas Muhammadiyah Purwokerto \\ arifsermas@gmail.com
}

\begin{abstract}
Abstrak
Stroke merupakan penyakit neurologis yang diakibatkan adanya kelainan pada peredaran darah otak yang dapat berlangsung selama 24 jam atau lebih. Status neurologis penderita stroke dapat diukur dengan National Institutes of Health Stroke Scale (NIHSS). Pemeriksaan ini untuk menilai kemajuan hasil perawatan pasien stroke yang terdiri dari 11 komponen. Pemberian posisi kepala $30^{\circ}$ disertai dengan passive range of motion (PROM) merupakan kombinasi tindakan yang berfungsi memaksimalkan oksigenasi jaringan serebral dan kemampuan motorik, sehingga penyembuhan pada pasien stroke akan menjadi lebih cepat. Tujuan dalam penelitian ini yaitu untuk mengetahui pengaruh kombinasi posisi kepala $30^{\circ}$ dan PROM terhadap penurunan skor NIHSS pada pasien stroke. Rancangan penelitian ini menggunakan Quasi experimental dengan pendekatan pretest posttest control group desain. Sampel berjumlah 14 responden yang dibagi menjadi 2 kelompok. Hasil penelitian menunjukkan ada pengaruh kombinasi posisi kepala $30^{\circ}$ dan PROM terhadap skor NIHSS pada pasien stroke dengan $\mathrm{P}$ value $=0,002(\alpha<0,05)$. Saran dari penelitan ini perawat dapat menerapkan kombinasi posisi kepala $30^{\circ}$ dan PROM sebagai intervensi mandiri keperawatan pada pasien stroke untuk dalam upaya memberikan penyembuhan yang lebih cepat dan menjadikan salah satu SOP dalam perawatan pasien stroke dirumah sakit.
\end{abstract}

Kata kunci : NIHSS; passive range of motion; posisi kepala $30^{\circ}$; stroke

PENDAHULUAN

$\begin{array}{lll}\text { Stroke merupakan penyakit } & \text { (Dewanto, 2009). Stroke di Indonesia } \\ \text { neurologis yang diakibatkan adanya } & \text { merupakan penyakit nomor tiga yang } \\ \text { kelainan pada peredaran darah otak yang } & \text { mematikan setelah jantung dan kanker. }\end{array}$
dapat berlangsung selama 24 jam atau lebih (Dewanto, 2009). Stroke di Indonesia mematikan setelah jantung dan kanker. 
Insiden stroke di Amerika Serikat diperkirakan lebih dari 700.000 tiap tahun dan yang meninggal lebih dari 160.000 tiap tahunnya (Sofyan, Sihombing, \& Hamra, 2013).

Penyebab tingginya angka kematian dan kecacatan pada stroke diakibatkan oleh proses patofisiologis yang terjadi dalam jaringan otak. Aliran darah ke otak yang terganggu dapat berpengaruh terhadap hemodinamik serebral. Hemodinamik serebral dipengaruhi oleh pembuluh darah serebral/cerebral blood flow (CBF) (Junaidi, 2011).

Masalah utama pada stroke iskemik yaitu gangguan CBF. Proses ini berlanjut dan dapat menyebabkan terjadinya edema cerebri. Guna mengurangi dampak iskemik, maka tindakan memperbaiki $\mathrm{CBF}$ dan metabolisme merupakan tindakan yang sangat penting dan segera dilakukan (Husna \& Dalhar, 2017).

Tindakan keperawatan yang dapat dilakukan untuk memfasilitasi peningkatan CBF dan memperbaiki metabolisme serebral diantaranya monitor tanda vital, pemberian posisi, aktivitas dan mempertahankan suhu tubuh normal. Tindakan memberi posisi tidur pasien stroke dan aktivitas merupakan tindakan mandiri perawat. Posisi kepala pasien stroke berpengaruh pada hemodinamik serebral yang nantinya akan meningkatkan hasil perawatan pasien stroke (Lestari \& Satria, 2015).

Posisi kepala ditinggikan berada diatas aksis vertikal jantung menyebabkan cairan cerebrospinal terdistribusikan kembali menuju keruang spinal subaraknoid dan memfasilitasi terjadinya aliran balik vena (Dewi, 2019). Tindakan pemberian posisi kepala pasien stroke merupakan tindakan sangat penting. Peninggian kepala dapat menurunkan intracranial pressure (ICP), namun disisi lain juga dapat meningkatkan ICP dan iskemik serebral yang menyebabkan gangguan autoregulasi serebral (Kusuma \& Anggraeni, 2019).

Aktivitas pada pasien stroke dapat memperbaiki haemodinamik serebral. Salah satu dari tindakan pemberian aktivitas tersebut adalah passive range of motion (PROM). Pergerakan pada ekstremitas akan menghasilkan peningkatan aliran darah bagian sisi yang berlawanan pada motor korteks dan somatosensoris. Proses tersebut didasari oleh adanya perubahan aktivitas actrocyte yang meningkatkan nitris oxide (Hasanah, 2017).

Tindakan pemberian posisi dan aktivitas merupakan tindakan rutin perawat dalam melakukan asuhan keperawatan paasien stroke. Pemberian posisi kepala 
ditinggikan $30^{\circ}$ pada pasien stroke iskemik dan dilakukan PROM secara periodik (Hasan, 2018). pemberian posisi kepala pada pasien stroke iskemik yaitu pertahankan posisi tirah baring dua sampai tiga hari, posisi anatomis atau pemberian posisi kepala ditinggikan $15^{\circ}$ sampai $30^{\circ}$. Pemberian tindakan aktivitas yaitu latohan pergerakan sendi secara pasif setiap 2 sampai 4 jam. Kedua tindakan tersebut tujuannya untuk memperbaiki hemodinamik serebral yang pada akhirnya meningkatkan hasil perawatan pasien stroke (Ekacahyaningtyas, Setyarini, Agustin, \& Rizqiea, 2017).

Status haemodinamik pada pasien stroke diukur dengan National Institutes of Health Stroke Scale (NIHSS) (Black \& Hawks, 2005). NIHSS merupakan suatu pengkajian yang dilakukan pada pasien stroke untuk menilai kemajuan hasil perawatan pasien stroke yang terdiri dari 11 komponen. NIHSS banyak digunakan pada pusat pelayanan stroke untuk menilai tingkat keparahan dari stroke yang dialami seorang pasien. Perbedaan nilai NIHSS saat masuk dan keluar merupakan indikator keberhasilan perawatan pasien stroke (Smeltzer et al., 2008).

Berdasarkan permasalahan diatas maka peneliti tertarik untuk mengambil judul "pengaruh kombinasi posisi kepala $30^{\circ}$ dan PROM terhadap penurunan skor NIHSS pada pasien stroke".

Tujuan dalam penelitian ini yaitu diketahuinya pengaruh kombinasi posisi kepala $30^{\circ}$ dan PROM terhadap penurunan skor NIHSS pada pasien stroke.

\section{METODE}

Penelitian ini menggunakan desain Quasi-eksprimental melalui pendekatan pretest-posttest control group desain. Penelitian ini membandingkan skor NIHSS sebelum dan sesudah perlakuan diberikan. Instrument yang digunakan dalam penelitian ini yaitu NIHSS yang terdiri dari 11 komponen penilaian. NIHSS tidak saja menilai derajat deficit neurologis pada pasien stroke, melainkan juga memudahkan komunikasi antara tenaga medis dengan pasien, mengenali kemungkinan adanya sumbatan pembuluh darah, menentukan prognosis awal dan komplikasi serta menetapkan tindakan yang diperlukan. Jumlah sampel dalam penelitian ini sebanyak 14 responden yang dibagi menjadi kelompok intervensi dan kelompok kontrol. Posisi kepala $30^{\circ}$ dan PROM dilakukan 3 kali dalam sehari selama 4 hari.

Analisa data pada penelitian ini menggunakan uji dependen t-test untuk 
melihat perbedaan selisih rata-rata skor NIHSS sebelum dan setelah perlakuan.
HASIL

1. Karakteristik responden

Tabel 1 Distribusi karakteristik responden

\begin{tabular}{|c|c|c|}
\hline Variabel & f & $\%$ \\
\hline \multicolumn{3}{|l|}{ Usia } \\
\hline 20-30 tahun & 1 & 7 \\
\hline 31-40 tahun & 2 & 14 \\
\hline 41-50 tahun & 2 & 14 \\
\hline 51-60 tahun & 5 & 36 \\
\hline $61-70$ tahun & 3 & 22 \\
\hline$>71$ tahun & 1 & 7 \\
\hline \multicolumn{3}{|l|}{ Jenis Kelamin } \\
\hline Laki-laki & 8 & 57 \\
\hline Perempuan & 6 & 43 \\
\hline
\end{tabular}

Berdasarkan Tabel 1 diatas usia terbanyak yaitu kelompok usia 51-60 tahun sebanyak 5 orang (36\%). Jenis kelamin lakilaki lebih banyak (57\%) dibandingkan perempuan $(43 \%)$.
2. Perbedaan rerata skor NIHSS sebelum dan setelah perlakuan pada kelompok intervensi dan kelompok kontrol

Tabel 2 Perbedaan rerata skor NIHSS sebelum dan setelah perlakuan pada kelompok intervensi dan kelompok control

\begin{tabular}{ccccc}
\hline Kelompok & Skor NIHSS & Mean & SD & P value \\
\hline \multirow{2}{*}{ Intervensi } & Sebelum & 7,00 & 1,732 & \multirow{2}{*}{0,002} \\
\cline { 2 - 4 } & Sesudah & 3,71 & 1,380 & \multirow{2}{*}{0,172} \\
\hline \multirow{2}{*}{ Kontrol } & Sebelum & 7,43 & 2,070 & $0,1,864$ \\
\hline
\end{tabular}

Berdasarkan tabel diatas diketahui bahwa rerata skor NIHSS pada kelompok intervensi sebelum dilakukan perlakuan sebesar 7,00 dan rerata skor NIHSS setelah diberikan perlakuan sebesar 3,71. Terlihat selisih rerata skor NIHSS sebelum dan setelah perlakuan sebesar 3,29 dengan $\mathrm{p}=$
0,002 $(\alpha<0,05)$, maka didapatkan kesimpulan bahwa terdapat perbedaan signifikan antara skor NIHSS sebelum dan setelah dilakukan perlakuan.

Hasil dari kelompok kontrol menunjukkan bahwa rerata skor NIHSS sebelum perlakuan sebesar 7,43 dan setelah 
perlakuan rerata skor NIHSS sebesar 6,86. Selisih rerata skor NIHSS sebelum dan setelah perlakuan sebesar $0,57 \mathrm{p}=0,172$ $(\alpha>0,05)$, maka didapatkan kesimpulan bahwa tidak ada perbedaan signifikan antara rerata skor NIHSS sebelum dan setelah dilakukan perlakuan.

\section{PEMBAHASAN}

Berdasarkan hasil penelitian didapatkan bahwa usia 51-60 terbanyak dibandingkan kelompok usia yang lainnya dan jenis kelamin laki-laki lebih banyak dibandingkan perempuan. Hasil penelitian ini sejalan dengan penelitian Delima, Miharja \& Ghani (2016) yang menyatakan bahwa proporsi kejadian stroke pada usia diatas 45 tahun meningkat tajam. Usia diatas 45 tahun lebih beresiko 10,23 kali dibandingkan dengan usia 15-44 tahun (Delima, Mihardja, \& Ghani, 2016). Usia merupakan salah satu factor resiko stroke yang tidak dapat dirubah dan memiliki factor yang paling kuat. Insiden kejadian stroke akan meningkat seiring dengan meningkatnya usia seorang tanpa memandang jenis kelamin dan suku budaya (Patricia, Kembuan, \& Tumboimbela, 2015).

Hasil penelitian ini juga sejalan dengan (Patricia et al., 2015) yang menyatakan bahwa penderita stroke iskemik lebih banyak laki-laki di RSUP Prof. Dr. R. D. Kandou. Kejadian ini disebabkan pada usia subur perempuan memiliki hormone esterogen yang dapat melindungi dari penyakit yang disebabkan oleh penyakit jantung dan stroke, namun setelah menopause perempuan akan memiliki resiko yang sama dengan laki-laki (Heart, 2003).

Hasil penelitian ini terdapat perbedaan skor NIHSS sebelum dan sesudah dilakukan kombinasi tindakan posisi kepala $30^{\circ}$ dan PROM dengan selisih skor 3,29. Penelitian ini sejalan dengan penelitian Pertami, dkk (2019) yang menyebutkan bahwa terdapat peningkatan nilai saturasi oksigen dengan diberikan posisi elevasi $30^{\circ}$ (Pertami, Munawaroh, \& Rosmala, 2019). Penelitian Rahayu (2016) menyebutkan bahwa terdapat pengaruh latihan range of motion terhadap kemampuan motorik pada pasien post stroke (K. I. N. Rahayu, 2016).

Pemberian posisi kepala $30^{\circ}$ yaitu mengatur posisi kepala lebih tinggi dari jantung. Pemberian posisi kepala tersebut akan memperlancar aliran darah ke otak serta meningkatkan aliran darah otak. (Pertami et al., 2019). Hal tersebut sesuai dengan tori menurut Summers, et al (2009) yang menunjukkan bahwa memposisikan kepala lebih tinggi akan meningkatkan aliran 
darah di otak dan oksigenasi jaringan serebral yang maksimal. (Summers et al., 2009).

Latihan PROM akan membuat ransangan yang dapat meningkatkan aktivitas dari kimiawi neuromuskuler dan muskuler. Kontraksi otot akan terjadi apabila terdapat rangsangan pada neuromuskuler terutama pada serat saraf otot ekstremitas. ATP yang dihasilkan melalui mekanisme muskulus terutama pada otot polos ekstremitas akan meningkatkan metabolisme pada metakonderia yang dimanfaatkan oleh otot ekstremitas sebagai energy untuk meningkatkan tonus dan kontrasi otot polos ekstremitas (Khonsary, 2017).

Pemberian posisi kepala $30^{\circ}$ disertai dengan PROM merupakan kombinasi tindakan yang berfungsi memaksimalkan oksigenasi jaringan serebral dan kemampuan motorik, sehingga penyembuhan pada pasien stroke akan menjadi lebih cepat.

$$
\text { Indikator dalam mengetahui }
$$
perbaikan pasien stroke dapat dinilai menggunakan NIHSS. NIHSS merupakan alat penilaian yang sistematis untuk menilai tingkat keparahan atau berhubungan dengan defisit neurologis yang dialami pada penderita stroke. Pemeriksaan ini meliputi aspek neurologis yaitu kesadaran, motoric, sensorik dan fungsi luhur (Saudin \& Rajin, 2017).

NIHSS terdiri dari 11 komponen penilaian yang terdiri dari tingkat kesadaran, gerakan bola mata, lapang pandang, kelemahan pada wajah, motorik tangan, motorik kaki, ataksia, sensori, bahasa, disartria, dan tidak ada atensi pada bagian tubuh tertentu. NIHSS memiliki skor maksimum 42 dan skor minimum 0 . Interpretasi dari NIHSS yaitu: sangat berat; $>25$, berat; 14-25, sedang; 5-14, dan ringan; < 5 (Jojang, Runtuwene, \& PS, 2016).

Skor NIHSS yang semakin rendah menunjukkan tingkat keparahan stroke semakin ringan. Pemeriksaan ini dapat untuk memprediksi keluaran jangka panjang dan jangka pendek pada pasien stroke (M. Rahayu, Rakhmani, Raisa, \& Rahmah, 2018).

\section{KESIMPULAN}

Hasil penelitian ini dapat disimpulkan terdapat perbedaan yang signifikan skor NIHSS sebelum dan setelah diberikan kombinasi posisi kepala $30^{\circ}$ dan PROM pada pasien stroke dengan nilai $\mathrm{P}$ value $0,002(\alpha<0,05)$.

\section{SARAN}


Penelitian ini menyarankan agar perawat dapat menerapkan kombinasi posisi kepala $30^{\circ}$ dan PROM sebagai intervensi mandiri keperawatan pada pasien stroke untuk dalam upaya memberikan penyembuhan yang lebih cepat dan menjadikan salah satu SOP dalam perawatan pasien stroke dirumah sakit.

\section{DAFTAR PUSTAKA}

Black, J., \& Hawks, J. (2005). Medicalsurgical nursing, St. Louis: Elsevier Saunders.

Delima, D., Mihardja, L. K., \& Ghani, L. (2016). Faktor risiko dominan penderita stroke di Indonesia. Indonesian Bulletin of Health Research, 44(1), 20146.

Dewanto, G. (2009). Panduan praktis Diagnosis dan tata laksana penyakit saraf.

Dewi, Y. A., \& Mkes, S. K. (2019). Buku Tht. . Bandung: Departemen Ilmu Kesehatan THT-KL FKUP/RSHS.

Ekacahyaningtyas, M., Setyarini, D., Agustin, W. R., \& Rizqiea, N. S. (2017). Posisi Head Up $30^{\circ}$ Sebagai Upaya Untuk Meningkatkan Saturasi Oksigen Pada Pasien Stroke Hemoragik Dan Non Hemoragik. Adi Husada Nursing Journal, 3(2), 55-59.

Hasan, A. K. (2018). Study Kasus Gangguan Perfusi Jaringan Serebral Dengan Penurunan kesadaran Pada Klien Stroke Hemoragik Setelah Diberikan
Posisi Kepala Elevasi $30^{\circ}$. Babul Ilmi Jurnal Ilmiah Multi Science Kesehatan, 9(2).

Hasanah, K. (2017). Penerapan Latihan Rom Aktif Terhadap Kekuatan Otot Pada Pasien Stroke Non Hemoragik Di Rsud Krmt Wongsonegoro Kota Semarang. Universitas Muhammadiyah Semarang.

Heart, C. (2003). Stroke Foundation (2010) A Perfect Storm Of Heart Disease Looming On Our Horizon. Annual Report. Canadian Heart Health Initiative.

Husna, U., \& Dalhar, M. (2017). Pathophysiology And Management Of Cerebral Edema. Malang Neurology Journal, 3(2), 94-107.

Jojang, H., Runtuwene, T., \& PS, J. M. (2016). Perbandingan NIHSS Pada Pasien Stroke Hemoragik Dan NonHemoragik Yang Rawat Inap Di Bagian Neurologi RSUP Prof. Dr. RD Kandou Manado. e-CliniC, 4(1).

Junaidi, I. (2011). Stroke, waspadai ancamannya: Penerbit Andi.

Khonsary, S. A. (2017). Guyton and Hall: textbook of medical physiology. Surgical neurology international, 8

Kusuma, A. H., \& Anggraeni, A. D. (2019). Pengaruh Posisi Head Up 30 Derajat Terhadap Nyeri Kepala Pada Pasien Cedera Kepala Ringan. Jurnal Ilmu Keperawatan dan Kebidanan, 10(2), 417-422.

Lestari, T., \& Satria, A. P. (2015). Analisis Praktik Klinik Keperawatan pada Pasien Cedera Kepala Sedang 
dengan Post Craniotomy Decompression di Ruang High Care Unit RSUD Abdul Wahab Sjahranie Samarinda Tahun 2015.

Patricia, H., Kembuan, M. A., \& Tumboimbela, M. J. (2015). Karakteristik Penderita Stroke Iskemik Yang Di Rawat Inap Di Rsup Prof. Dr. RD Kandou Manado Tahun 2012-2013. e-CliniC, 3(1).

Pertami, S. B., Munawaroh, S., \& Rosmala, N. W. D. (2019). Pengaruh Elevasi Kepala 30 Derajat Terhadap Saturasi Oksigen Dan Kualitas Tidur Pasien Stroke. Health Information: Jurnal Penelitian, 11(2), 134-145.

Rahayu, K. I. N. (2016). Pengaruh pemberian latihan range of motion (rom) terhadap kemampuan motorik pada pasien post stroke di rsud gambiran. Jurnal keperawatan, 6(2).

Rahayu, M., Rakhmani, A. N., Raisa, N., \& Rahmah, K. A. A. (2018). Hubungan Mean Arterial Blood Pressure Dengan Keluaran Pasien Stroke Trombotik Yang Dinilai Dengan Skor Nihss. Majalah Kesehatan FKUB, 5(3), 160-170.

Saudin, D., \& Rajin, M. (2017). Metode Pengkajian Neurologis Menggunakan National Institute of Health Stroke Scale (NIHSS) pada pasien stroke di ruang Instalasi Gawat Darurat di RSUD DR Iskak Tulungagung. Jurnal Edunursing, 1(1).

Smeltzer, S. C., Bare, B. G., Hinkle, J., Cheever, K., Townsend, M. C., \& Gould, B. (2008). Brunner and Suddarth's textbook of medicalsurgical nursing 10th edition: Philadelphia: Lipincott Williams \& Wilkins.

Sofyan, A. M., Sihombing, I. Y., \& Hamra, Y. (2013). Hubungan umur, jenis kelamin, dan hipertensi dengan kejadian stroke. Medula, 1(1).

Summers, D., Leonard, A., Wentworth, D., Saver, J. L., Simpson, J., Spilker, J. A.,. Mitchell, P. H. (2009). Comprehensive overview of nursing and interdisciplinary care of the acute ischemic stroke patient: a scientific statement from the American Heart Association. Stroke, 40(8), 2911-2944. 